\title{
La tricícleta: una máquina de construir y deconstruir historias
}

\section{The tricicleta: a machine to construct and deconstruct stories}

\author{
DOI: http://dx.doi.org/10.17981/cultedusoc.12.1.2021.13
}

Recibido: 15 de abril de 2020. Aceptado: 12 de agosto de 2020. Publicado: 28 de diciembre de 2020

\author{
Efraín Muñoz-Galíndez \\ Corporación Universitaria Autónoma del Cauca. Popayán (Colombia) \\ efrainm_22@hotmail.com \\ Cristian Alexis Lasso-Quilindo \\ Corporación Universitaria Autónoma del Cauca. Popayán (Colombia) \\ cristianlasso96@gmail.com \\ Sandro Pérez-Muñoz \\ Corporación Universitaria Autónoma del Cauca. Popayán (Colombia) \\ sandro.perez,m@uniautonoma.edu.co
}

Para citar este artículo:

Muñoz-Galíndez, E., Lasso-Quilindo, C. y Pérez-Muñoz, S. (2021). La tricícleta: una máquina de construir y deconstruir historias. Cultura, Educación y Sociedad, 12(1), 203-216. DOI: http://dx.doi.org/10.17981/cultedusoc.12.1.2021.13

\section{Resumen}

El deporte adaptado es un escenario que permite a las personas en situación de discapacidad mejorar su autoestima y sentirse vitales, por tanto, el presente artículo tiene como objetivo comprender cómo el ciclismo adaptado ha influenciado en la trayectoria de vida de los deportistas adscritos a la Liga Deportiva de Parálisis Cerebral del Cauca, Colombia (LIDEPACC). Se fundamenta en un enfoque cualitativo a través del método biográfico; las técnicas de recolección de datos fueron el diario de campo y la entrevista biográfica. Los datos acopiados se analizaron bajo los lineamientos de la teoría fundada. En los hallazgos emergió la categoría selectiva, - La tricícleta: Una máquina de construir y deconstruir historias-, donde se evidencia cómo el deporte ha contribuido para que los deportistas puedan vencer su principal obstáculo, sentirse discapacitados. Como conclusión, resalta que la discapacidad se percibe de acuerdo al contexto social donde se vive y el deporte adaptado es la mejor terapia para contribuir al saneamiento físico y psicológico.

Palabras clave: Cuerpo; deporte adaptado; discapacidad; capital simbólico

\section{Abstract}

Adapted sport is a scenario that allows people with disabilities to improve their self-esteem and feel vital, therefore, this article aims to understand how adapted cycling has influenced the life trajectory of the athletes attached to the League Sports Center for Cerebral Palsy of Cauca, Colombia (LIDEPACC). It is based on a qualitative approach through the biographical method; the data collection techniques were the field diary and the biographical interview. The collected data were analyzed under the guidelines of the founded theory. In the findings, the selective category emerged, -The tricyclete: A machine to build and deconstruct stories-, where it is evident how sport has contributed so that athletes can overcome their main obstacle, feeling disabled. In conclusion, it highlights that disability is perceived according to the social context where one lives and adapted sport is the best therapy to contribute to physical and psychological sanitation.

Keywords: Body; adapted sports; disability; symbolic capital 


\section{INTRODUCCIÓN}

El hombre es un ser sociable que se comunica de diferentes formas (Duch, 1998; Idárraga, 2012; Juřík, 2015), y el cuerpo juega un rol importante porque expresa lo que siente o piensa, además es la parte visible del sujeto que da cuenta si es convencional o tiene alguna discapacidad. En palabras de Bourdieu (1991), los cuerpos se clasifican según su condición física en legítimos o no legítimos, esta concepción es producto de las dinámicas del capitalismo que promueve el consumismo y valora el cuerpo según la capacidad de producción, desfavoreciendo a las personas con discapacidad por tener un cuerpo no apto-feo-enfermo-inútil, en otras palabras, un cuerpo "no legítimo" que no cumple con los estándares establecidos, un cuerpo "legítimo" que se caracteriza por ser sano-aptobello-útil.

Esta concepción de cuerpo invisibiliza socialmente a las personas con discapacidad, vulnerándoles derechos como el trabajo y la educación, por mencionar algunos, ampliando las brechas de desigualdad y menoscabando en su identidad personal (Goffman, 2001; Carbonell, 2019; Contreras, Encinas y Gómez, 2017). Este fenómeno social tiende a agudizarse porque hay una cultura indolente, donde prima la competencia y por ende la negación del otro (Ferrante y Dukuen, 2017), quebrantando a quienes buscan aproximarse al cuerpo legítimo para sentirse vitales y ser aceptados y reconocidos socialmente, acumulando capital simbólico y económico (Palacios y Bariffi, 2007; Vargas-Pineda y López-Hernández, 2020).

Ésta es la realidad de miles de personas con discapacidad (Organización Mundial de la Salud, OMS, 2011), que buscan una oportunidad de demostrar sus competencias para desempeñarse socialmente, igual o mejor que sus semejantes; es importante para ellos evidenciar como los imaginarios sociales los estigmatizan e invisibilizan, sin desconocer que hay algunas excepciones por las características de la discapacidad (Goffman, 2001; García y Ospina, 2008).

En Colombia, alrededor del 15\% de la población, está en situación de discapacidad (Correa y Castro, 2016), cifras que evidencian la necesidad de reflexionar y tomar decisiones que promuevan la inclusión, puesto que se está inmerso en una sociedad excluyente, pensada y estructurada para personas convencionales o con un cuerpo legítimo (García y Ospina, 2008; Muñoz y Montes, 2017). Si bien, se han promovidos escenarios para atender este tipo de población, son insuficientes. No obstante, desde el campo del deporte, los deportes adaptados han sido eje fundamental, para agenciar la inclusión y dar participación activa a las personas con discapacidad (OMS, 2011; Montilla, 2019).

Dentro de la variedad de deportes (individuales y de conjunto) recreativos y competitivos, están el voleibol sentado, natación, ciclismo adaptado, entre otros, transformándose en eje fundamental para sanar las heridas físicas y psicológicas, se generan espacios de inclusión y reconfiguración de los proyectos de vida (Organización de las Naciones Unidas, ONU, 2003; Muñoz y Montes, 2017), toda vez que permite acumular capital simbólico, valga aclarar, reconocimiento social que eleva el estatus y los visibiliza socialmente. Ahí reside la iniciativa de pesquisar cómo el ciclismo adaptado, influye en la trayectoria de vida de los deportistas con discapacidad de la Liga de Parálisis Cerebral del Cauca (LIDEPACC). 


\section{FundAMENTACIÓN TEÓRICA}

\section{La discapacidad: un tema álgido por analizar}

La discapacidad es una condición física o cognitiva, adquirida o congénita, que altera el desarrollo de la persona (Gómez y Castillo, 2016; Ferrante y Dukuen, 2017). El estigma hacia la población con discapacidad, los ha invisibilizado socialmente (Bourdieu, 1991), ampliando las brechas de desigualdad e impidiendo que accedan a derechos fundamentales. Esto es el resultado de una cultura miope, guiada por los estándares de cuerpo del sistema capitalista y que legitima la sociedad (García y Ospina, 2008; Idárraga, 2012; Míguez, 2017).

Al respecto, Ferrante y Ferreira (2008), retomando postulados teóricos de Bourdieu, aluden que "la posición de un agente en el espacio social y, específicamente, en el propio de las sociedades capitalistas, está determinada por su trayectoria social, ascendente o descendente, y por sus propiedades corporales, sean éstas socialmente elogiadas o estigmatizadas" (pp. 1-2). En otras palabras, el capital económico y simbólico determinan el despliegue de las personas, poniendo en desventaja o desposesionando de capital simbólico a los sujetos con discapacidad (Ferrante y Dukuen, 2017), por sus características corporales y la falta de oportunidades sociales que les permita acumular tal capital.

Por ende, "el cuerpo socialmente objetivado es un producto social que debe sus propiedades distintivas a sus condiciones de producción" (Bourdieu citado por Ferrante y Ferreira, 2008, p. 7). Esta dinámica invisibiliza socialmente a las personas que por enfermedades congénitas o accidentes, conviven con un cuerpo rechazado por los cánones de la normalidad. Cánones como expresión de una cultura de violencia simbólica y estructural, por cuanto complejizan la vida para poder aproximarse al cuerpo legítimo y lograr la aceptación del otro y la sociedad.

En este sentido, la discapacidad se transforma en un estigma, con el cual deben vivir las personas que buscan acercarse a un cuerpo "legítimo", inalcanzable por la vulnerabilidad económica o social (Goffman, 2001; Le Breton, 2002). Al respecto, Ferrante y Ferreira (2011) señalan que "poseer un cuerpo no legítimo parece significar una desposesión en términos de capital simbólico que atravesaría al conjunto de las clases sociales; en el caso de las personas con discapacidad motora, las condenaría a una especie de muerte social" (p. 86). Así, el capital simbólico dinamiza el despliegue de los sujetos y configura la identidad personal, en el constructo dinámico y biográfico representado en cómo me veo y cómo me ven los otros. En palabras de Bourdieu (1990), es el habitus quien determina las condiciones y acciones de las personas en el campo, en el caso de los sujetos la discapacidad y las trayectorias sociales pueden restarle o acumular capital simbólico, es decir, la discapacidad se vive de acuerdo con las líneas biográficas de cada persona.

En cuanto al tipo de discapacidad congénita o adquirida, diferentes estudios (Segura, Martínez-Ferrer, Guerra y Barnet, 2012; Díaz et al., 2018), la clasifican en: física, cognitiva, psíquica, intelectual y Parálisis Cerebral (PC). Las personas que clasifican con PC, son aquellas con trastornos (musculo-esqueléticos, sensoriales, perceptivos, etc.), los cuales afectan el movimiento, equilibrio y coordinación, debido a una lesión neurológica no progresiva y no inmutable (Jiménez, 2017; Solís y Real, 2019). Independientemente del tipo de discapacidad, se tiene el reto de sobrepasar o acortar las brechas de desigualdad social, y el deporte adaptado es por excelencia un escenario de inclusión que amplía las trayectorias de vida para superarse. 


\section{Los beneficios del deporte adaptado}

Ante la vulnerabilidad social en que están inmersas las personas con discapacidad, el deporte adaptado es una de las tantas oportunidades donde pueden sentirse aceptados y reconocidos. Éstos siguen las reglas de los deportes convencionales y son pensados para que las personas con discapacidad los practiquen, y a su vez promuevan la inclusión sin afectar el objetivo del deporte (Reina, 2014; Montilla, 2019). El deporte adaptado fue considerado después de la segunda guerra mundial, como medio terapéutico para trabajar con militares que sufrieron heridas físicas y psicológicas a causa de la guerra (Soláns, 2014; Ferrante, 2014). En la actualidad, hay deportes individuales y de conjunto que se practican de forma recreativa o competitiva, por personas que tienen alguna discapacidad congénita o adquirida.

Independientemente de la finalidad, se rescata que el deporte promueve inclusión y debe promulgarse como un derecho, en especial para personas con discapacidad (ONU, 2006; Macías y González, 2012). Estudios anteriores (Muñoz y Montes, 2017), evidencian que el voleibol sentado es para los deportistas más que un deporte, una familia donde aceptaron el cuerpo mutilado, siendo autónomos y visibilizándose socialmente mediante la participación en campeonatos, en otras palabras, dio sentido a sus vidas al acumular capital simbólico. Es importante resaltar que los deportes adaptados, reconfiguran los cuerpos de las personas con discapacidad, pues al interior, los deportistas crean lazos de amistad y la resiliencia se presenta como mecanismo de sanación, para reorientar los proyectos personales y familiares (Camargo y Forero, 2016; Muñoz y Montes, 2017).

En la investigación de Duarte, Torres y Nieto (2010), ejecutada con una deportista colombiana paralímpica de natación, concluyen que el deporte es un medio de transformación de la vida de los sujetos, convirtiéndose en un espacio para desarrollar y vivir nuevas experiencias y aprendizajes. En este sentido, el deporte adaptado permite a los deportistas acumular capital simbólico como base para reconfigurar su identidad personal y buscar nuevos horizontes en una sociedad excluyente (Ferrante, 2013; Ferrante y Silva, 2017). Ser parte de un grupo conformado por personas con las mismas características corporales, es un factor dinamizador de los procesos de resiliencia, pues se identifican con el otro, comparten algunas necesidades y no se sienten excluidos, ello promueve seguridad y autoconfianza para emprender otros caminos. De igual manera, Ferrante (2014), señala que "internacionalmente se mantiene firme la convicción de que el deporte adaptado, es uno de los principales elementos para garantizar la inclusión de las personas con discapacidad" (p. 422).

De los deportes adaptados, que han permitido reconfigurar el tejido social y resignificado el cuerpo no legítimo y la vida de quienes lo practican, está el ciclismo adaptado o paracycling, cuyo origen data de 1988 en los Juegos Paralímpicos de Seúl (Giménez, 2014). En la actualidad, existen diferentes modalidades y categorías, clasificándose según el tipo de discapacidad: bici a mano (H1-H4), ciclismo (C1-C5), tándem (B) y triciclo o triciclismo (T1T2). La modalidad de triciclismo, abarca personas con PC (hemiplejia, triplejia, atetosis) que generan déficit de equilibrio y coordinación de pedaleo (Giménez, 2014; Jiménez, 2017; Díaz et al., 2018). Por esto, el uso de la tricícleta proporciona estabilidad en los deportistas en las pruebas deportivas (Giménez, 2014). La práctica de este deporte de forma competitiva 
exige física y psicológicamente a los deportistas, por ello deben tener entrenamientos de forma regular y seguir las directrices del entrenador, que son acordes a la funcionalidad física y a los objetivos trazados. Valga aclarar, se requiere de los deportistas compromiso y dedicación, al igual que los deportes convencionales.

\section{Metodología}

En correspondencia con el propósito del artículo orientado a comprender cómo el ciclismo adaptado ha influenciado en la trayectoria de vida de los deportistas, se optó metodológicamente por el enfoque cualitativo, que por su naturaleza epistemológica permite la comprensión e interpretación del objeto de estudio, (Barrantes, 2007). Junto a lo anterior, se utilizó el método biográfico, el cual permitió acceder de forma privilegiada, al testimonio que los deportistas hacen a su trayectoria de vida (Sanz, 2005; Soláns, 2014).

Las narraciones permiten "dar un orden al conjunto de los sucesos pasados, encontrando un hilo conductor que establezca las relaciones necesarias entre lo que el narrador era y lo que hoy es" (Bolívar, Domingo y Fernández, 2001, p. 2). Para acopiar los datos se utilizó el diario de campo y la entrevista biográfica, ya que son flexibles y permiten recolectar información relevante, desde el relato y acciones de los sujetos investigados (Scribano, 2008).

Para hacer los primeros acercamientos con los deportistas, se les acompañó a entrenamientos en el gimnasio y en las salidas de ruta, de ahí surgieron los primeros diarios de campo que además de acopiar información condujo a generar la confianza suficiente para pasar a las entrevistas, en ellas se hizo un conversatorio guiado por preguntas orientadoras, para ahondar en la trayectoria de vida en atención al pasado, presente y futuro. Los diarios de campo y entrevistas fueron grabados y transcritos, para ser analizados mediante el análisis de contenido, siguiendo los lineamientos de la teoría fundada (Strauss y Corbin, 2002). Valga aclarar, se inició haciendo el primer análisis para obtener las categorías abiertas, estas se agrupan de acuerdo con la similitud de la información y así construir las categorías axiales, finalmente las categorías axiales se agrupan para que emerja la categoría selectiva. En este artículo, la categoría selectiva es "La tricícleta: Una máquina de construir y deconstruir historias", sustentada por las categorías axiales: a) La discapacidad es más mental que física y b) El deporte adaptado: generador de procesos de resiliencia.

La investigación se desarrolló con deportistas con PC, practicantes de triciclismo, adscritos a la LIDEPACC y se seleccionaron bajo los siguientes criterios de inclusión:

1. Personas con discapacidad adquirida, porque permite observar y analizar cómo el accidente que le genera la discapacidad influye en su proyecto de vida e identidad, y a su vez cómo el deporte adaptado dinamiza otras formas de ver y vivir su nueva realidad.

2. Deportistas que pertenezcan a la LIDEPACC desde hace tres años o más, en la modalidad de triciclo.

3. Que hayan obtenido reconocimientos en juegos nacionales representado al departamento.

4. Que hayan conformado su propia familia. 
Fueron dos deportistas quienes cumplieron los criterios de selección; para salvaguardar su identidad, en los relatos se identifican como sujeto 1 (Sj1) y sujeto 2 (Sj2). Ellos, desde hace 4 años, forman parte de la Fundación Paso a Paso de la ciudad de Popayán (CaucaColombia), en la disciplina de triciclismo, en pruebas de ruta y contrarreloj, representan al departamento en juegos nacionales, acopiando medallas de oro, plata y bronce en las competencias. El Sj1 adquirió la discapacidad a los 17 años en una salida pedagógica del colegio, fue víctima del conflicto armado, en una emboscada guerrillera recibió varios impactos de bala en su cuerpo, una de ellas quedó incrustada en la cabeza ocasionando PC, en la actualidad tiene su empresa y conformó su propia familia. Por su parte, el Sj2 cuando tenía 31 años, sufrió un accidente de tránsito que le generó PC, para esa época había conformado su familia y en la actualidad, trabaja conduciendo un carro publicitario. En el ranking nacional son top 4 y 3 respectivamente.

En este sentido, para lograr el objetivo del estudio, salvaguardar la identidad de los sujetos y durante el trabajo de campo, se retomaron los criterios éticos propuestos por Hammersley \& Atkinson (1994): consentimiento informado, privacidad, perjuicio, explotación y consecuencias para investigaciones futuras.

En relación a la importancia del triciclismo para los deportistas entrevistados, es oportuno ahondar en la categoría selectiva: "La tricícleta: una máquina de construir y deconstruir historias", sustentada por las categorías axiales: La discapacidad, es más mental que física y El deporte adaptado: generador de procesos de resiliencia.

\section{Hallazgos y Discusión}

La tricícleta es un artefacto que permite la movilidad de personas "normales" o con algún tipo de discapacidad, hay quienes la usan como medio de transporte o para practicar deporte, independientemente de su uso, permite avanzar por los caminos que dan sentido a la vida de quienes la conduce. Para los actores consultados, la tricícleta los ha llevado a encontrar nuevos horizontes; se rompe con los estigmas de la discapacidad en una sociedad excluyente, donde lograron reconfigurar sus cuerpos física y psicológicamente a pesar de las adversidades.

El Paracycling, deporte adaptado del ciclismo convencional es un espacio donde los deportistas viven nuevas experiencias, desafiando su discapacidad para enfrentar los desafíos y retos sociales, acumulando paulatinamente capital simbólico y, consecuentemente, resignificar sus cuerpos para sobrellevar el estigma por tener un cuerpo ilegítimo. $\mathrm{Al}$ respecto los protagonistas señalan:

Para mí el triciclismo lo es todo, es parte de mí vida, porque estoy teniendo triunfos iy es fenomenal!, el salir en el periódico, entonces es muy gratificante (Sj2-TE) ${ }^{1}$.

Los referentes los corrobora el otro deportista, cuando hace referencia al triciclismo como su motor para seguir trabajando:

\footnotetext{
${ }^{1}$ Los párrafos citados, son relatos que emergieron de las entrevistas y diarios de campo de la investigación. Se colocan fuera del texto para diferenciarlos. El código que acompaña a los relatos, permite evidenciar el sujeto que lo manifiesta y la técnica que se utilizó para acopiar la información, por ejemplo, Sj1: Sujeto número uno; TE: Entrevista; TD: Diario de campo. Estos códigos se han utilizado, para salvaguardar la identidad de las personas que participaron de la investigación.
} 
En este momento es muy importante, porque gracias al deporte no sólo he viajado a lo largo del país, representando al Cauca y a Colombia, eso me hace sentir muy contento y con más ganas de seguir trabajando con el triciclismo, es todo para mí, el motor (Sj1-TE).

El triciclismo ha sido para los deportistas entrevistados, un medio para sentirse vitales y reconocidos, acopiando capital simbólico como línea biográfica ascendente. Testimonio de ello, se ratifica en salir y ocupar los medios de comunicación, por los logros alcanzados dentro y fuera del campo de competencia, además de convertir el deporte en el motor de sus proyectos de vida. Este deporte les ha devuelto la autonomía y seguridad en sí mismos, dejando a un lado la idea de poseer un cuerpo discapacitado. Varios autores (Macías y González, 2012; Cardoso \& Sacomori, 2014; Haudenhuyse, Hayton, Parnell, Verkooijen \& Delheye, 2020) concuerdan que el deporte adaptado es una oportunidad, para reconfigurar el tejido social y el cuerpo no legítimo de las personas, al representar un espacio de integración, superación y motivación. Para ahondar en esta temática esbozada en la presente categoría selectiva, se invita a leer las siguientes categorías axiales donde a través de sus relatos dan cuenta cómo el deporte adaptado ha influido positivamente en la autoestima e identidad de los deportistas.

\section{La discapacidad, es más mental que física}

El cuerpo es signo de prestigio u opresión y "es un medio de expresión altamente restringido, puesto que está muy mediatizado por la cultura y expresa la presión social a soportar" (Martínez, 2004, p. 130). Por ello, es importante develar cómo las personas con alguna deficiencia física o cognitiva se ven afectadas, y en virtud de ello, cómo el deporte ha influido en sus proyectos de vida al reorientar sus proyectos personales y familiares. Adquirir una nueva condición física que desencadena una discapacidad, propicias restricciones para participar y desarrollarse activamente en los diferentes roles sociales, pensados y estructurados para personas convencionales.

De ahí la importancia de los deportes adaptados, para subsanar las heridas físicas y psicológicas que propicia la sociedad con los actos de segregación. En el caso de los deportistas de la LIDEPACC, el triciclismo les ha permitido sobrepasar los estigmas de la discapacidad y continuar con sus propósitos personales y familiares; algunos episodios ocasionaron caos y desorden en la vida de los sujetos al despojarse del cuerpo legítimo. Si bien los accidentes difieren por el escenario y la complejidad de los hechos, hay una similitud entre ellos, vivir con un cuerpo con el que no estaban acostumbrados. A continuación, los deportistas señalan cómo adquirieron la discapacidad:

Fue una emboscada guerrillera donde caímos varios compañeros del colegio y policías, recibí 4 impactos de bala y 7 impactos de esquirla de granada, uno de los proyectiles de bala lo tengo en la cabeza, está alojado cerca del cerebelo, pasa por el hemisferio izquierdo, y se quedó incrustado en el cerebelo en la masa encefálica, eso me genera una pérdida de movilidad en la parte derecha o también llamada hemiplejia (Sj1-TE).

No menos traumático, el accidente del otro deportista, quien con un poco de nostalgia expresa como su vida dio un giro inesperado: 
Fue un trauma craneoencefálico a raíz de un accidente que tuve hace unos 8 años, a mí me atropelló un carro y yo iba en una moto y el carro me arrolló y la verdad no me acuerdo de más (Sj2-TE).

Los relatos permiten entrever, las situaciones que cambiaron de forma transcendental los rumbos y proyectos de vida de estas personas. Estos episodios llenos de incertidumbre dejaron secuelas en el cuerpo y la mente, puesto que adaptarse a una nueva condición requiere tiempo y tolerancia. La adaptación y aceptación de la nueva condición física, toma tiempo y tolerancia propia y de los semejantes, donde se debe estructurar de nuevo la existencia en el marco social y personal, permitiendo fortalecer la autoestima mediante la superación de los estigmas sociales (Yanci, Iturricastillo, Lozano y Granados, 2015). Vivir con una discapacidad, en palabras de Bourdieu (1991) con un cuerpo no legítimo, los reta a sobre pasar los obstáculos sociales y culturales que los pueden invisibilizar socialmente, en este sentido, el deporte se convierte en el mejor aliado porque los hacen sentir vitales y activos. En los siguientes relatos, los deportistas narran cómo se acercaron a la bicicleta, posterior al accidente.

Un día mirando a mi hijo montar bicicleta, cogí la bicicleta de él y experimente una sensación interesante de libertad, me subí en ella con algo de dificultad, y cuando sentí el aire fluir en mi rostro, le dije a Dios que nunca más me iba a bajar de ella, y que iba a llegar a muchos lugares, los más lejanos y extremos posibles (Sj1-TD).

En el relato se evidencia que antes de acercarse al triciclo, el deportista tuvo contacto con una bicicleta convencional, por el contrario, el otro deportista se acercó directamente con el triciclo.

Después del accidente, el profesor me dijo que hiciéramos bicicleta y me preguntó ¿te gusta montar bicicleta? y le dije ¡sí, a mí me gusta!, entonces me puso a montar en triciclo y hacer trabajos de pesas y me rehabilitó (Sj2-TE).

El reencuentro con la bicicleta, les permitió remembrar emociones y sentimientos de años pasados, y descubrir capacidades para afrontar retos asociados a su condición física; el ser humano, está ligado por las libertades o capacidades que tiene su cuerpo (Augé, 2009). Para los dos deportistas, la bicicleta es más que un artefacto, una motivación para desplazarse y es la cómplice que los acompaña a construir y deconstruir historias, dando sentido a la vida (Hoyos y Ruiz, 2017; Muñoz y Montes, 2017). Motivación subyacente en la acumulación de bienes simbólicos, que se expresan en triunfos y reconocimiento social por su quehacer deportivo. Después de varios años acompañados de la tricícleta, la conciben como el motor para su rehabilitación:

Es una oportunidad de poder brillar deportivamente, siento una satisfacción de ser bueno en la disciplina y que lo dicho por los médicos, que había un compromiso del 90\% de mi cuerpo, que no podía volver a caminar otra vez, es una demostración de que, si se podía lograr, la satisfacción es bastante grande, es la posibilidad de demostrar que a pesar de todo lo que parecía, todo lo que no se podía hacer, se pudo hacer (Sj1-TE).

Físicamente y mentalmente estoy bien, parezco un muchacho de 15 (risas), porque estoy haciendo deporte, el deporte a mí me ha rehabilitado mucho, ya estoy caminando bien y es que como yo era antes, pero yo camino bien y es gracias al deporte (Sj2-TE). 
El deporte adaptado les ha permitido, hallar un poco de ese cuerpo legítimo caracterizado por ser útil y estético, pero sobre todo encontrarse consigo mismo para concientizarse que tienen capacidades y hacer frente a la segregación social, ser autónomos e independientes, para visibilizarse y sentirse con derechos y deberes como cualquier persona en la sociedad (Wheeler et al., 1999; Ferrante y Silva, 2017). Al respecto, Le Breton (2002) considera que la liberación del cuerpo con discapacidad será efectiva cuando haya desaparecido la convicción y preocupación por el cuerpo estético, y se atienda las acciones orientadas a generar capital simbólico para propiciar una línea biográfica ascendente.

Para los deportistas entrevistados, la participación en triciclismo ha permitido hacer catarsis y generar procesos de resiliencia, yuxtaponiendo el estigma por no tener un cuerpo legítimo; toda vez que la tricícleta es el "vehículo movido por el deseo, cuyo motor son los sueños" (Tizón, 2013, p. 14). Lo anterior en palabras de uno de los entrevistados:

Uno de mis sueños era ser ciclista profesional para representar a mi departamento y mi país, lo cual estoy cumpliendo y me ha llevado a ser campeón y subcampeón nacional, una experiencia que viví representando y portando el uniforme del departamento del Cauca fue en un viaje en avión, donde me encontraba con entrenadores y deportistas profesionales de Colombia, para mí es un orgullo sentirme a nivel con estas personas (Sj1-TE).

Para los deportistas el deporte adaptado ha sido eje fundamental, para sentirse a la par con los deportistas convencionales de Colombia, motivándolos a seguir pedaleando por los sueños deportivos y personales. Parafraseando a Bourdieu (1991), acopian capital simbólico que les inyecta un poco de motivación, para llegar a lo más alto del podio y consecuentemente, visibilizarse en lo deportivo, abonando a la trayectoria social ascendente, donde la aceptación personal, del otro y la sociedad mejora la autoestima. Lo anterior, se corrobora cuando los deportistas trazan metas a corto, mediano y largo plazo:

Mi sueño es ser campeón paralímpico, ya estoy cuchito cierto, yo podría ser el papá de ustedes (risas), pero yo sé que, si le gané al mejor del mundo, que puede ser mi nieto, puedo lograr mi objetivo (Sj2-TE).

Es evidente que los sueños, son los propulsores para la superación, tal como señala Ferrante (2010), el deporte representa un "indicador profundo de la esencia moral de la persona, constituye el elemento más valorado y generador de ganancias en bienes simbólicos dentro y fuera del campo" (p. 997). Ello es lo que mantiene firme a los dos deportistas, porque encuentran en el triciclismo, una atmósfera donde no hay estigmatización entre sus pares y les reconocen su labor como deportistas, pero sobre todo, porque el deporte les ha dado la oportunidad de demostrarse a sí mismos que pueden alcanzar objetivos personales; la discapacidad no es un impedimento para ello. Lo anterior, evidencia las conductas resilientes desde los procesos deportivos.

\section{El deporte adaptado: generador de procesos de resiliencia}

El despliegue de las personas, dentro de los diferentes escenarios sociales depende en cierta medida, de su cuerpo y de los valores ascendentes o descendentes configurados durante la trayectoria de vida. Al respecto, Ferrante (2013), sostiene que "cada cuerpo poseerá su valor en función de cuán alejado esté del cuerpo [no legítimo] y de cuánto se esfuerce por superarse" (p. 173). En otras palabras, vivir con una discapacidad física o 
cognitiva, genera desventajas que desdibujan los proyectos personales. No obstante, muchas de las personas con discapacidad han logrado superar las barreras del estigma social y así han logrado su reconocimiento por lo que son y no por su condición, se han concientizado que los límites son mentales. En este sentido, el deporte es una herramienta terapéutica a través del cual las personas con discapacidad logran superar miedos y vuelvan a reorientar su proyecto de vida.

Yo le pongo voluntad a las cosas, sino le pusiera voluntad estuviera postrado en una cama o andando en una silla de ruedas. Gracias al profesor, él me rehabilitó y me dijo hágale y empezó a hacerme terapias, y como él coordina la liga, me vinculó al triciclismo (Sj2-TE).

Los deportistas reconocen que el triciclismo, brindó los espacios para superarse a sí mismos y hacer de la discapacidad, una oportunidad para sobresalir deportivamente "ser conscientes de que la vida está llena de obstáculos y que para superarlos es necesario tener voluntad y creer en sí mismo" (Muñoz y Montes, 2017, p. 8). Vivir con una discapacidad adquirida no es tarea fácil, se requiere de fuerza de voluntad para recuperar la confianza en sí mismo y transitar otros caminos, en este sentido, el deporte adaptado es el puente que contrarresta las brechas para seguir con los proyectos de vida.

Demostré a la gente que a pesar de las dificultades y todo lo que han dicho los médicos, uno puede salir adelante y hacer cosas grandes, esa es mi motivación y mi familia; quiero demostrarles a mis hijos, las cosas que se pueden lograr, a pesar de las dificultades que uno pueda tener (Sj1-TE).

No estoy limitado, toda va en la cabeza (señalándose la sien), yo sé que tengo mi limitación, pero trató de hacer las cosas bien (Sj2-TE).

La principal limitante para una persona con discapacidad es creer que su invalidez es una etiqueta (estigma), por ello, es de resaltar a estos deportistas que a pesar de las adversidades, han logrado superar la principal discapacidad, creerse discapacitados. Lo anterior, da cuenta que la resiliencia es un proceso para transformar la forma de ver y vivir la vida (Galindo \& Mateus, 2017; Hurtado, Simmonds y Yanza, 2018), sobre todo, cuando se adquiere o nace con una discapacidad física. Ante esta realidad, el deporte adaptado es el mejor aliado para general la resiliencia en esta población. Al respecto, Ferrante (2014) reitera que el deporte adaptado permite demostrar a la sociedad que una persona con discapacidad (PC), no subyace con una enfermedad mental, sino con una afección motriz, cuyo esfuerzo y voluntad puede ser superado y subsanado en el margen personal y social. En este escenario, el deporte por sus bondades desde lo motriz, contribuye a mejorar la movilidad y aporta a la rehabilitación física, necesaria para contrarrestar problemas de coordinación, lateralidad, equilibrio, fuerza, resistencia, entre otras capacidades condicionales y perceptivo-motrices, desde lo social contribuye a la inclusión y sobrepasar problemas de autoestima o identidad personal.

Esfuerzo y voluntad por superarse, es lo que demuestran estos deportistas en entrenamientos y competencias, donde la limitación pasa a un segundo plano para desafiar las adversidades y demostrarse que los límites van más allá de la condición física, dándole sentido a la vida (Muñoz y Montes, 2017). Lo anterior, porque el deporte adaptado mejora la autoestima y las relaciones inter e intrapersonales (Sherrill, 2004), para superar las barreras de sentirse estigmatizados. El reconocimiento que hace la sociedad a los deportistas 
con discapacidad, les permite acumular capital simbólico que genera una línea biográfica ascendente, porque dejan de ser vistos como "inválidos" a ser un referente de superación personal y como deportistas élite, porque el deporte adaptado desde lo competitivo requiere de esfuerzo, dedicación y disciplina, al igual que los deportes convencionales.

Mucha gente le gusta lo que yo hago, porque están bien representados, entonces la gente dice: tienes que entrenar ¡me motivan más! para que salga a montar tricícleta y me dan ánimos iy bacano?!, nosotros hemos estado por el parque y todo el mundo nos mira y es chévere, todo ésto es chévere, móntese en una tricícleta de esas y vera (risas) (Sj2-TE).

Los relatos evidencian que la principal motivación para continuar pedaleando ante las adversidades es el reconocimiento y apoyo de las personas que presencian sus actos deportivos, en palabras de Ferrante y Ferreira (2011), el reconocimiento permite acopiar capital simbólico y consecuentemente visibilizarse socialmente, esto genera un estatus deportivo y social. De igual manera, da confianza en sí mismo para superar los retos, que son la motivación para continuar en la disciplina deportiva.

Siempre he tenido esas ganas de salir adelante y hacer cosas que nadie más las hace y demostrarles que sí puedo. Un día cogí la tricícleta y miré que yo tenía la capacidad de resistencia, me escribí a los Guinness Word Récords proponiendo batir un récord de distancia, me respondieron ¡sí!, que lo hiciera en 12 horas, me estoy preparando, quiero estar en las mejores condiciones para cuando lo haga (Sj1-TE).

El relato permite entrever que el deportista, tiene sed de logro, siendo su principal motivación sus deseos de superación; esto contrarresta la percepción errada de que las limitaciones físicas dominan y anquilosan la mente. Estos deportistas con discapacidades adquiridas y estigmatizados e invisibilizados por su condición, han encontrado en el triciclismo el camino de superación y motivación. Por ello hay que resaltar que, el deporte es un escenario de inclusión y libertad, asimismo es un medio de rehabilitación para las personas con discapacidad, y del mismo modo, constituye un medio de integración y resignificación personal y social (Torralba, Braz y Rubios, 2017; Darcy, Ollerton \& Grabowski, 2020). El deporte adaptado es un escenario para la promoción de una cultura incluyente, por tanto, debe brindarse los espacios y tiempos para que las personas con discapacidad se involucren y disfruten de ellos, porque son contextos que van más allá de lo deportivo, generando rehabilitación física y psicológica, necesarias para afrontar o desafiar los obstáculos estructurales y sociales.

\section{Conclusiones}

Después de adentrarse en la subjetividad de los deportistas y comprender cómo el deporte adaptado ha influido en sus trayectorias de vida, se expone a modo de conclusiones que adquirir una discapacidad física cambia drásticamente los proyectos de vida, porque se vive en una sociedad discapacitante diseñada para las personas convencionales, donde se invisibiliza a quienes no cuentan con un cuerpo legítimo, es decir, sano-productivo-esbelto. La práctica de deporte adaptado tiene muchas bondades, entre ellas sobresalen, la mejora

\footnotetext{
2 Léxico coloquial para referirse a agradable o bien.
} 
en la autoestima y generar procesos de resiliencia. La exigencia del deporte permite reflexionar acerca de límites más mentales que físicos.

En este sentido, el deporte adaptado permite trabajar con personas con discapacidad que han sido víctimas del conflicto armado, de accidentes o que, por razones ajenas nacieron con una discapacidad; se identifican habilidades y sentirse activos, pero sobre todo reconocidos por los logros deportivos y no por su condición física. La practica de un deporte adaptado en personas con discapacidad física, devuelve la confianza en sí mismo y permite blindarse de los actos y palabras estigmatizantes a las que se exponen, por no tener un cuerpo acorde a los cánones establecidos por la sociedad.

El deporte adaptado brinda a sus deportistas la posibilidad de visibilizarse socialmente y, consecuentemente, acumular capital simbólico, porque son reconocidos por sus logros deportivos, contribuyendo a la trayectoria de vida ascendente y logren salir del anonimato asociado a condiciones de discapacidad.

\section{REFERENCIAS}

Augé, M. (2009). Elogio de la bicicleta. Barcelona: Gedisa.

Barrantes, R. (2007). Investigación: un Camino al Conocimiento. Un Enfoque Cuantitativo y Cualitativo. Costa Rica: Editorial Universidad Estatal a Distancia.

Bolívar, A., Domingo, J. y Fernández, M. (2001). La investigación biográfico-narrativa en educación. Enfoque y metodología. Madrid: La Muralla.

Bourdieu, P. (1991). El sentido práctico. Madrid: Taurus.

Bourdieu, P. (1990). Sociología y Cultura. Madrid: Grijalbo.

Camargo, D. y Forero, C. (2016). La inclusión deportiva en Colombia: Una mirada desde los actores. Estudio de caso. Cuerpo, Cultura y Movimiento, 6(2), 143-165. https://doi. org/10.15332/s2248-4418.2016.0002.03

Carbonell, G. (2019). El movimiento de vida independiente en España. Revista Española de Discapacidad, 7(2), 201-214. https://doi.org/10.5569/2340-5104.07.02.12

Cardoso, F. \& Sacomori, C. (2014). Resilience of athletes with physical disabilities: A crosssectional study. RPD, 23(1), 15-22. Disponible en https://revistes.uab.cat/rpd/article/ view/v23-n1-cardoso-sacomori

Contreras, M., Encinas, V. y Gómez, M. (2017). Dificultades de contratación en el mercado de trabajo para las personas con discapacidad: Análisis desde la perspectiva de género. Intersticios, 11(2), 71-81. Disponible en http://www.intersticios.es/article/ view/17716

Correa, L. y Castro, M. (2016). Discapacidad e inclusión social en Colombia. Informe alternativo de la Fundación Saldarriaga Concha al Comité de Naciones Unidas sobre los derechos de las personas con discapacidad. [Informe Alternativo]. Bogotá, D.C.: Editorial Fundación Saldarriaga Concha. Recuperado de https://www.saldarriagaconcha. org/wp-content/uploads/2019/01/pcd_discapacidad_inclusion_social.pdf 
Darcy, S., Ollerton, J. \& Grabowski, S. (2020). "Why Can’t I Play?”: Transdisciplinary Learnings for Children with Disability's Sport Participation. Social Inclusion, 8(3), 209-223. http://dx.doi.org/10.17645/si.v8i3.2750

Díaz, E., Huete, A., Leardy, L., Mendoza, N., Ocete, C., Orive, N. y Solves, J. (2018). Libro blanco del deporte de personas con discapacidad en España. Madrid: Cinca.

Duarte, R., Torres, C. y Nieto, N. (2010). Historia de vida de una deportista paralímpica colombiana. Revista Educación física y deporte, 29(1), 95-101. Disponible en https:// revistas.udea.edu.co/index.php/educacionfisicaydeporte/article/view/7165

Duch, L. (1998). Mito, interpretación y cultura. Introducción a la logomítica. Barcelona: Herder.

Ferrante, C. (2014). Cuerpo, discapacidad y estigma en el origen del campo del deporte adaptado de la Ciudad de Buenos Aires, 1950-1961: ¿una mera interiorización de una identidad devaluada? Revista História, Ciências, Saúde-Manguinhos, 21(2), 421-437. https://dx.doi.org/10.1590/S0104-59702014000200004

Ferrante, C. (2013). Cuerpo, deporte y discapacidad motriz en la Ciudad de Buenos Aires. Tensiones entre la reproducción y el cuestionamiento a la dominación. Revista Española de Discapacidad, 1(1), 159-178. https://dx.doi.org/10.5569/2340-5104.01.01.08

Ferrante, C. (2010). Rengueando el estigma: Modos de ser, pensar y sentir (se) discapacitado construidos desde la práctica deportiva adaptada. Revista Brasileira de Sociología da Emoção, 9(27), 980-1009. Recuperado de http://www.cchla.ufpb.br/rbse/RBSE\%20 v\%209.n.27.dez\%202010.pdf

Ferrante, C. y Dukuen, J. (2017). "Discapacidad” y opresión: Una crítica desde la teoría de la dominación de Bourdieu. Revista de Ciencias Sociales DS-FCS, 30(40), 151-168. Disponible en http://hdl.handle.net/11336/57746

Ferrante, C. y Ferreira, M. (2011). Cuerpo y habitus: el marco estructural de la experiencia de la discapacidad. Intersticios, 5(2), 85-101. Disponible en http://www.intersticios.es/article/view/8888

Ferrante, C. y Ferreira, M. (2008). Cuerpo, discapacidad y trayectorias sociales: dos estudios de caso comparados. Revista de Antropología Experimental, (8), 403-428. Recuperado de https://www.um.es/discatif/documentos/FerranteFerreira2.pdf

Ferrante, C. y Silva, J. (2017). "Rengo es el que tiene pelotas": discapacidad motriz, deporte adaptado y masculinidad hegemónica en la ciudad de Buenos Aires. Forum: Qualitative Social Research, 18(3), 1-22. https://dx.doi.org/10.17169/fqs-18.3.2442

Galindo, J. \& Mateus, C. (2017). Características de familias resilientes frente a los efectos de violencia politica y social en Colombia: San Jose del Playon: Resistir y vivir. Cultura Educación y Sociedad, 8(2), 49-60. https://doi.org/10.17981/cultedusoc.8.2.2017.04

García, L. y Ospina, J. (2008). Imaginarios de las personas en situación de discapacidad en torno a la actividad física. Revista Ciencias de la Salud, 6(2), 51-63. Disponible en https://revistas.urosario.edu.co/index.php/revsalud/article/view/482

Giménez, T. (2014). Ciclismo adaptado. Barcelona: Formación Alcalá. 
Goffman, E. (2001). Estigma: La identidad deteriorada. Buenos Aires: Amorrortu.

Gómez, E. y Castillo, D. (2016). Sociología de la discapacidad. Revista de Ciencias Sociales, (40), 176-194. http://dx.doi.org/10.32399/rtla.10.40.158

Hammersley, M. \& Atkinson, P. (1994). Etnografía. Métodos de Investigación. Barcelona: Paidós.

Haudenhuyse, R., Hayton, J., Parnell, D., Verkooijen, K. \& Delheye, P. (2020). Boundary Spanning in Sport for Development: Opening Transdisciplinary and Intersectoral Perspectives. Social Inclusion, 8(3), 123-128. http://dx.doi.org/10.17645/si.v8i3.3531

Hoyos, A. y Ruíz, L. (2017). Otra mirada a la discapacidad en la práctica del ciclismo recreativo. Revista de Investigaciones UCM, 17(29), 114-128. https://dx.doi.org/10.22383/ ri.v17i29.92

Hurtado, D., Simmonds, M. y Yanza, P. (2018). Queremos seguir otro camino: Memorias del conflicto armado en niños y niñas en situación de desplazamiento en Popayán. Popayán: Editorial Universidad del Cauca.

Idárraga, C. (2012). Discurso contemporáneo sobre la estética del cuerpo y su repercusión psicológica en sujetos adolescentes. Cultura Educación y Sociedad, 3(1), 23-32. Disponible en https://revistascientificas.cuc.edu.co/culturaeducacionysociedad/article/ view/953

Jiménez, A. (2017). Efectos de las terapias ecuestres en personas con parálisis cerebral. Revista Española de Discapacidad, 5(2), 171-184. https://doi.org/10.5569/23405104.05.02.09

Juřík, V. (2015). How body influences memory: The embodied aspects in retrieval of autobiographical memories. Annales Psychologici, 2(16), 28-38. Disponible en http://hdl. handle.net/11222.digilib/134

Le Breton, D. (2002). La sociología del cuerpo. Buenos Aires: Nueva Visión.

Macías, D. y González, I. (2012). Inclusión social de personas con discapacidad física a través de la natación de alto rendimiento. Apunts. Educación Física y Deportes, 110, 26-35. https://dx.doi.org/10.5672/apunts.2014-0983.es.(2012/4).110.03

Martínez, A. (2004). La construcción social del cuerpo en las sociedades contemporáneas. Papers, 73, 127-152. https://dx.doi.org/10.5565/rev/papers/v73n0.1111

Míguez, M. (2017). Discapacidad en lo social. Un enfoque desde las corporalidades. Almenara, (9), 61-67. Disponible en https://sites.google.com/site/almenararevistasociologia/home/almenara-no-9---2017

Montilla, M. (2019). Inclusión y competición: Adaptaciones para disminuir las barreras de participación de un grupo de gimnastas con discapacidad intelectual en gimnasia rítmica y propuesta de reglamento específico para la competición. Retos, (36), 552-560. https://doi.org/10.47197/retos.v36i36.69283

Muñoz, E. y Montes, S. (2017). Voleibol sentado: un deporte que da sentido a la vida. Educación Física y Ciencia, 19(1), 1-19. https://doi.org/10.24215/23142561e019 
ONU. (2006). Convention on the rights of persons with disabilities and optional protocol. [A/RES/61/106]. Recuperdo de https://www.un.org/disabilities/documents/convention/convoptprot-e.pdf

ONU. (2003). Deporte para el desarrollo y la paz. [Online]. Recuperado de https://www. unicef.es/sites/unicef.es/files/Deporte06.pdf

OMS. (2011). Informe mundial sobre la discapacidad. [Online]. Recuperado de https:// www.who.int/disabilities/world_report/2011/summary_es.pdf

Palacios, A. y Bariffi, F. (2007). La discapacidad como una cuestión de derechos humanos. Una aproximación a la Convención Internacional sobre los Derechos de las Personas con Discapacidad. Madrid: Cinca.

Reina, R. (2014). Inclusión en deporte adaptado: dos caras de una misma moneda. Revista Psychology, Society, \& Education, 6(1), 55-67. Disponible en http://ojs.ual.es/ojs/index. php/psye/article/view/508/486

Sanz, A. (2005). El método biográfico en investigación social: potencialidades y limitaciones de las fuentes orales y los documentos personales. Asclepio, 57(1), 99-116. https:// doi.org/10.3989/asclepio.2005.v57.i1.32

Segura, J., Martínez-Ferrer, J., Guerra, M. y Barnet, S. (2012). Creencias sobre la inclusión social y el deporte adaptado de deportistas, técnicos y gestores de federaciones deportivas de deportes para personas con discapacidad. Revista Iberoamericana de Psicología del Ejercicio y el Deporte, 8(1), 120-144. Disponible en https://www.ripedonline.com/articles/beliefs-about-the-social-inclusion-and-the-adaptedsports-of-athletes-coaches-and-managers-of-sportfederations-for-people.pdf

Scribano, A. (2008). La investigación social cualitativa. Buenos Aires: Prometeo.

Sherrill, C. (2004). Adapted physical activity, recreation and sports: Crossdisciplinary and lifespa ( 6 Ed.). New York: McGraw-Hill.

Soláns, A. (2014). Historias de vida de deportistas paralímpicas. Trayectorias biográficas. Apunts, 3(117), 84-90. https://doi.org/10.5672/apunts.2014-0983.es.(2014/3).117.09

Solís, P. y Real, S. (2019). Estado actual de investigación en parálisis cerebral y envejecimiento: revisión sistemática. Revista Española de Discapacidad, 7(2), 103-122. https://doi.org/10.5569/2340-5104.07.02.06

Strauss, A. y Corbin, J. (2002). Bases de la investigación cualitativa: técnicas y procedimientos para desarrollar la teoría fundamentada. Medellín: UdeA.

Tizón, E. (2013). Pide tres deseos. En, VVAA, Diez bicicletas para treinta sonámbulos. (pp. 9-15). Madrid: Demipage.

Torralba, M., Braz, M. y Rubios, M. (2017). Motivos de la práctica deportiva de atletas paralímpicos españoles. Revista de Psicología del Deporte, 26(1), 49-60. Recuperado de https://archives.rpd-online.com/article/download/v26-n1-torralba-vieira-rubio/15808489-1-PB.pdf 
Vargas-Pineda, D. y López-Hernández, O. (2020). Experiencias de artistas con discapacidad frente a la promoción de la inclusión social. Arte, individuo y sociedad, 32(1), 31-44. https://doi.org/10.5209/ARIS.60622

Wheeler, G. D., Steadward, R. D., Legg, D., Hutzler, Y., Cambell, E. \& Johnson, A. (1999). Personal investment in disability sport careers: An internacional study. Adapted Physical Activity Quarterly, 16(3), 219-237. https://doi.org/10.1123/apaq.16.3.219

Yanci, J., Iturricastillo, A., Lozano, L. y Granados, C. (2015). Análisis de la condición física de jugadores nacionales de baloncesto en silla atendiendo a la clasificación funcional. RICYDE, 40(11), 173-185. https://dx.doi.org/10.5232/ricyde2015.04006

Efraín Muñoz-Galindez: Licenciado en Educación Básica con Énfasis en Educación Física, Recreación y Deporte. Magister en Educación con Mención en Política y Gestión Educativa. https://orcid.org/0000-0002-1824-5722

Cristian Lasso-Quilindro: Estudiante de IX semestre del programa de Entrenamiento Deportivo de la Corporación Universitaria Autónoma del Cauca (Colombia), adscrito al semillero de investigación SICRED (Semillero de Investigación Cuerpo, Recreación, Educación y Deporte) en calidad de investigador en formación. https://orcid.org/0000-00028497-3269

Sandro Pérez-Muñoz: Estudiante de IX semestre del programa de Entrenamiento Deportivo de la Corporación Universitaria Autónoma del Cauca (Colombia), adscrito al semillero de investigación SICRED (Semillero de Investigación Cuerpo, Recreación, Educación y Deporte) en calidad de investigador en formación. https://orcid.org/0000-0002-7644-5036 